\title{
ANÁLISES DE LIVROS
}

PARALISIA CEREBRAL: NEUROLOGIA, ORTOPEDIA, REABILITAÇÃO. CÉSAR LUIZ FERREIRA DE ANDRADE LIMA, LUIZ FERNANDO FONSECA. UM VOLUME $(21 \times 28 \mathrm{~cm})$ ENCADERNADO, COM 492 PÁGINAS. RIO DE JANEIRO, 2004: GUANABARA KOOGAN (TRAVESSA DO OUVIDOR 11, 20040-040 RIO DE JANEIRO RJ. E-mail: gbk@editoraguanabara.com.br).

Sem dúvida, todos concordam com o fato de que a Paralisia Cerebral, além de representar uma afecção de alta freqüência em Neurologia Infantil, constitui um grave impacto social, sobretudo nos países em desenvolvimento, nos quais a interação paciente / ambiente é insuficiente e inadequada. Considerando que os pacientes com Paralisia Cerebral apresentam comumente incapacidade para a marcha ou têm deficiência mental, além de poderem manifestar déficits sensitivos, sensoriais, comportamentais e epilepsia, entende-se facilmente a importância de uma abordagem profissional multidisciplinar e de um esquema terapêutico de reabilitação que, além de eficiente, deve ser mantido por tempo indeterminado, acarretando grave ônus financeiro, familiar ou institucional.

Assim, em nosso meio, a Paralisia Cerebral reveste-se de uma série de peculiaridades, que tornam este compêndio de César Luiz Andrade Lima e de Luiz Fernando Fonseca, o primeiro deste gênero, escrito com a colaboração de diversos profissionais de diferentes pontos do Brasil, leitura obrigatória para todos aqueles que lidam com este tipo de paciente. A relação dos pais e do paciente com a equipe multidisciplinar que inclui neurologista, pediatra, fisiatra, ortopedista, fisioterapeuta, terapeuta ocupacional, fonoaudiólogo, psicólogo, pedagogo, nutricionista, assistente social e odontó- logo, citando apenas os principais, deve ser estabelecida o mais precocemente possível para que se consiga uma orientação adequada, honesta e humana que previna, na medida do possível, não somente as seqüelas típicas da doença, como também desajustes familiares que pioram o prognóstico. Assim, é extremamente útil o enfoque que os autores deram à obra, no sentido de analisar o papel de cada membro desta equipe multidisciplinar, de modo que cada capítulo possa ser lido de forma independente para o esclarecimento de dúvidas específicas. A divisão nos três tópicos fundamentais, de Neurologia, Ortopedia e Reabilitação, facilita a consulta.

A parte de Neurologia, em particular, tem o mérito de, analisando os múltiplos fatores etiológicos e as chaves para o diagnóstico precoce, contribuir não somente para que se melhore a prevenção desta entidade tão limitante, como também para que desde cedo se estabeleça o tratamento paliativo que possa minorar seus efeitos perversos e melhorar a qualidade física e emocional do dia a dia das crianças afetadas.

Recomendo, portanto, a leitura do livro e sua utilidade como texto de consulta.

UMBERTINA CONTI REED

\section{A BRAIN FOR ALL SEASONS: HUMAN EVOLUTION AND ABRUPT CLIMATE CHANGE. WILLIAM H. CALVIN. UM VOLUME (14 x $21 \mathrm{~cm})$ COM 341 PÁGINAS. ISBN O 22609203 8. CHICAGO, 2002; THE UNIVERSTY OF CHICAGO PRESS (5801 SOUTH ELLIS AVENUE, CHICAGO, ILLINOIS 60627 USA).}

Este livro explica como mudanças súbitas do clima podem modificar espécies em maneiras dramáticas, favorecendo indivíduos e grupos com cérebros superiores e eliminando indivíduos e grupos com cérebros menos hábeis. Por exemplo, num período de somente 10 ou 20 anos a maior parte do deserto do Saara pode ser transformado em uma savana, com capim alto, algumas arvores e muitas pequenas lagoas; nos últimos 2 milhões de anos isso aconteceu muitas vezes. Animais, incluindo os hominídeos (os antepassados dos homens), aproveitaram disso, entrando e adaptando-se a este novo ambiente; mas somente os grupos com cérebros mais capazes podiam sobreviver e reproduzir nestas novas circunstâncias. Quando, alguns milhares de anos depois, esta região vasta de novo ficou subitamente (em 10 ou 20 anos) um deserto sem água e vegetação, o mesmo processo ocorreu uma vez mais, e somente os grupos com cérebros superiores podiam fugir para outros ambientes e lá so- 
brevivem e reproduzem. É assim que mudanças climáticas contribuem à evolução de cérebros mais e mais hábeis.

O autor é professor de psiquiatria e mudança de comportamento na Universidade de Washington School of Medicine em Seattle, Washington, EUA. Ele explora muitos assuntos ligados a este tópico central. Ele especula se a preservação dos cabelos em cima da cabeça, quando todos os outros cabelos do corpo foram perdidos, protegiam a cabeça e o cérebro contra superaquecimento, deixando o individuo sempre mais alerta, num ambiente onde a pessoa fica exposta ao sol muitas horas cada dia.

Nós temos uma tendência a pensar que grandes mudanças do clima precisam de séculos ou milênios. Professor Calvin explica como muitas pesquisas nos últimos 30 anos indicam claramente que mudanças dramáticas podem acontecer em uma ou duas décadas, e que isso aconteceu milhares de vezes nos últimos 5 milhões de anos. Cada mudança deu um impulso a mais para evolução de homens com mais inteligência. Ele trata extensivamente da próxima grande mudança do clima que os nossos netos e bisnetos vão experienciar. Esta mudança provavelmente vai ser rápida. O clima de "quente e chuvoso", em que nós estamos durante os últimos 8000 anos, vai modificar-se para um ambiente "frio e seco". Se a população humana não se preparar para adaptação (ou até prevenção) a esta mudança, o resultado vai ser uma diminuição enorme da população mundial devida à fome, e às guerras para obter comida no planeta. Esta mudança vai acontecer depois de um período, relativamente curto, de calor em que o "efeito estufa" é somente um dos fatores causais.

Professor Calvin escreve com uma clareza e erudição admiráveis, combinadas com um sentido de humor que alivia um pouco de tristeza do assunto. O livro tem uma bibliografia selecionada (Recommended Reading), um glossário e um índice completo.

A pergunta que fica é, se esta mudança vindoura vai ser um impulso para a evolução do cérebro humano ou um desastre imenso para nossa raça.

A.H. CHAPMAN ELZA A. NONATO

THE CRAFT OF RESEARCH. WAYNE C. BOOTH, GREGORY G. COLOMB, JOSEPH M. WILLIAMS. UM VOLUME $(14 \times 21 \mathrm{~cm})$ COM 329 PÁGINAS. ISBN 0252606568 5. CHICAGO, 2003: THE UNIVERSITY OF CHICAGO PRESS (5801 SOUTH ELLIS AVENUE, CHICAGO, ILLINOIS 60637 USA).

Este volume não trata das técnicas e procedimentos de pesquisas clínicas em medicina ou em outras áreas científicas. O seu campo é o das maneiras em que o pesquisador, ou grupos de pesquisadores, organiza os seus pensamentos, planeja seu projeto, e apresenta-o para leitores num artigo, ou relatório, ou livro. Este livro é bem escrito e fácil de ler; a primeira edição teve a vendagem extraordinária de 150000 exemplares.

No Prefácio, os três autores esboçam cinco aspectos básicos deste processo:

(1) como você pode transformar um interesse seu em um problema que merece investigação, e pode interessar a outras pessoas;

(2) como organizar os seus pontos de vista e as suas evidências numa maneira que vai convencer os leitores;

(3) como prever objeções que leitores vão ter e, em antecipação, responder a elas;

(4) como criar uma introdução e uma conclusão que resolvam a mais dura pergunta de tudo: Que tal?;

(5) Como ler e revisar o que você já escreveu com a meta de conseguir clareza nas mentes de leitores de todos os tipos e com diversas opiniões. Isso exige várias ou, talvez, muitas revisões, especialmente depois de consultas com colegas e leitores específicos ou típicos.

Nós, autores desta análise do livro, encaramos a situação assim. Quando você está escrevendo, sempre deve imaginar ter um leitor típico, ou talvez um grupo deles, à mesa, em frente de você. Eles estão perguntando, fazendo objeções, pedindo explicações e tentando entender de uma maneira clara e confortável. A sua tarefa é satisfazer essas exigências.

Nas suas 329 páginas, este livro trata detalhadamente de todos os aspectos deste assunto. Nesta segunda revisão, os autores escrevem extensamente sobre o uso da internet em pesquisas.

Nós fortemente recomendamos este excelente volume.

A.H. CHAPMAN SILVANA V. ALMEIDA 
NEUROPSICOLOGIA HOJE. VIVIAN MARIA ANDRADE, FLAVIA HELOÍSA DOS SANTOS, ORLANDO F.A. BUENO. UM VOLUME $(18 \times 25 \mathrm{~cm})$ EM BROCHURA, COM 454 PÁGINAS. SÃO PAULO, 2004: ARTES MÉDICAS (www.artesmedicas.com.br).

Os organizadores deste livro, psicólogos, pesquisadores de renome na área de neuropsicologia da Escola Paulista de Medicina da Universidade Federal de São Paulo, reuniram neste volume a experiência de mais de duas dezenas de autores (psicólogos, neurologistas e biólogos) de diversos Estados do Brasil e de alguns países da Europa. O resultado foi um conjunto de textos ricos, claros, didáticos e concisos.

A matéria abrange quatro partes. A primeira é dedicada a "conceitos gerais". São os temas desta parte: neuropsicologia hoje; aspectos instrumentais e metodológicos da avaliação psicológica; bases estruturais do sistema nervoso; inteligência, um conceito amplo; atenção; neurobiologia da atenção visual; funções executivas; memória e amnésia; neuropsicologia da linguagem. A Segunda parte, "infantil", trata dos temas: neuropsicologia do desenvolvimento; memória operacional e estratégias de memória; avaliação neuropsicológica infantil; reabilitação cognitiva pediátrica. Na terceira parte, "adulto", são estudados os seguintes temas: epilepsia; avaliação neuropsicológica em traumatismo craniencefálico; reabilitação neuropsicológica em lesão cerebral adquirida; aspectos cognitivos da esclerose múltipla; reabilitação: um modelo de atendimento interdisciplinar em esclerose múltipla; doença de Parkinson: aspectos neuropsicológicos; aspectos neuropsicológicos associados ao uso de cocaína. A Quarta parte, "idoso", inclui os temas: envelhecimento e memória; avaliação e reabilitação neuropsicológica no idoso; redução da assimetria hemisférica em adultos mais velhos: o modelo HAROLD.

Pela sua objetividade e atualidade, bem como pelo modo como foram tratados, devem ser salientados os temas sobre epilepsia, reabilitação na esclerose múltipla, doença de Parkinson e aspectos relativos ao uso de cocaína.

É um livro interessante, bem estruturado, feito para ajudar aqueles que procuram conhecimentos básicos na área de neuropsicologia. Conhecimentos básicos mas conceitualmente corretos e atuais. É leitura recomendada para psicólogos, neurologistas, clínicos gerais, pediatras e geriatras.

\section{LUÍS DOS RAMOS MACHADO}

EPILEPSIA.CARLOS A. M. GUERREIRO, MARILISA GUERREIRO. UM VOLUME (16 $\times 21 \mathrm{~cm})$ EM BROCHURA, COM 136 PÁGINAS. SÃO PAULO, 2004: EPM, EDITORA DE PROJETOS MÉDICOS (RUA LEANDRO DUPRET 204 / 91, 04025-010 SÃO PAULO SP. FAX 5575 2350. E-mail: epm@plugnet.com.br).

Este livro de 50 FAQ (Frequently Asked Questions) foi escrito pelo casal Carlos Alberto e Marilisa Guerreiro, ambos Professores Associados do Departamento de Neurologia da Faculdade de Ciências Médicas da Universidade Estadual de Campinas (UNICAMP), ambos notáveis epileptologistas de renome internacional. Neurologistas, motivam eles o grupo de colegas que cuidam especificamente do tema na UNICAMP. Apresentado o livro, destacam que o público alvo é o neurologista e, com ele, todo aquele que está envolvido no cuidado do epiléptico. Destacam ainda que foi possível manter a unidade dos pontos de vista, contidos ao longo de suas páginas, por ter sido escrito a duas mãos, ao mesmo tempo refletindo a experiência do casal e a harmonia do ambiente de estudos que imprimiram ao seu próprio lar.

São 50 as questões essenciais que abordam. Elas vão desde a clássica pergunta sobre o que é crise epiléptica e epilepsia, até aquelas relacionadas ao tratamento, passando pelos diferentes aspectos do diagnóstico, com ênfase aos do eletrencefalograma (EEG) e da classificação.

Finalizam a série de questões com dados acerca do prognóstico. Estes dados são desenvolvidos de modo abreviado e claro, apontando como fatores essencias o tipo de epilepsia, a etiologia, o tipo de crises, o EEG. Lembram que um prognóstico satisfatório é esperado em $50-70 \%$ dos pacientes, 20-30\% dos quais com síndromes benignas e autolimitadas.

Assim, conseguem os autores neste livro dar uma visão clara e precisa do que há de mais moderno e útil em epilepsia. Isto permite recomendar plenamente a leitura dele ao neurologista e ao que se inicia na especialidade, como o médico residente. 